\title{
PENGARUH MODEL PEMBELAJARAN VISUAL AUDITORIAL KINESTETIK (VAK) TERHADAP MOTIVASI DAN HASIL BELAJAR IPA BIOLOGI SISWA KELAS VIII SMP NEGERI 3 GUNUNGSARI TAHUN AJARAN 2015/2016
}

\section{THE EFFECT OF VISUAL AUDITORY KINESTHETIC (VAK) MODEL ON STUDENT'S MOTIVATION AND IPA BIOLOGY LEARNING ACHIEVEMENT AT GRADE VIII IN SMPN 3 GUNUNGSARI OF ACADEMIC YEAR 2015/2016}

\author{
Suryadin'), I Wayan Merta $^{2)}$, Kusmiyati ${ }^{3)}$ \\ ${ }^{1)}$ Mahasiswa Pendidikan Biologi FKIP Universitas Mataram \\ 2) 3)Dosen Pendidikan Biologi FKIP Universitas Mataram \\ Universitas Mataram, Jalan Majapahit No.62, Mataram, Indonesia \\ Email: dinsurya1@gmail.com
}

Received: 11 Maret 2017; Accepted: 28 Maret 2017

\begin{abstract}
Abstrak: Tujuan penelitian ini adalah untuk mengetahui pengaruh model pembelajaran Visual Auditorial Kinestetik (VAK) terhadap motivasi dan hasil belajar IPA Biologi siswa. Jenis penelitian ini merupakan penelitian eksperimen semu dengan desain penelitian nonequivalent control group design. Populasi penelitian ini adalah seluruh siswa kelas VIII SMPN 3 Gunungsari yang terbagi menjadi 3 kelas. Penentuan sampel dilakukan dengan teknik simple random sampling dan diperoleh kelas VIII B sebagai kelas eksperimen dan kelas VIII C sebagai kelas kontrol. Instrumen yang digunakan untuk mengukur motivasi belajar adalah angket motivasi belajar dan untuk mengukur hasil belajar adalah test obyektif (pilihan ganda). Data hasil penelitian dianalisis menggunakan uji-t dengan teknik independent sample t-test dengan taraf signifikansi 5\% yang dihitung dengan bantuan program SPSS 17 for Windows. Hasil penelitian terhadap motivasi belajar siswa setelah dilakukan uji beda menunjukan bahwa nilai t hitung $>\mathrm{t}$ kritik yaitu 3,411 > 1,680, sedangkan untuk hasil belajar diperoleh t hitung > t kritik yaitu 3,285 >1,680. Hal ini berarti bahwa penerapan model pembelajaran Visual Auditorial Kinestetik (VAK) berpengaruh secara signifikan terhadap motivasi dan hasil belajar IPA Biologi siswa.
\end{abstract}

Kata-Kata Kunci: Hasil Belajar, Model pembelajaran VAK, Motivasi Belajar

\begin{abstract}
The aim of this research is to examine the effect of visual auditory kinesthetic (VAK) models on student's motivation and IPA biology learning achievement at grade VIII in SMPN 3 Gunungsari of academic year 2015/2016. Type of research is quasi experimental and research design was nonequivalent control group design. Populations of this study were all students at grade VIII of academic year 2015/2016. Samples were determined by simple random sampling technique and obtained VIII B as experimental class and VIII C as control class. Instrument used to measure learning motivation was motivation questionnaire and to measure learning achievement was objective test (multiple choice). Data of students's motivation and learning achievement were analyzed by using t-test with independent sample t-test technique with a significance level of 5\% with the help of a computer using SPSS 17 for Windows. Result showed for student's learning motivation after hypothesis test obtained $\mathrm{t}$ value $>\mathrm{t}$ critical is 3,411>1,680, while for the learning achievement obtained $\mathrm{t}$ value $>\mathrm{t}$ critical is $3,285>1,680$. The results showed that implementation of visual auditory kinesthetic (VAK) models significantly affect for the biological Science student's motivation and learning achievement.
\end{abstract}

Keywords: Learning Achievement, Motivation, VAK model

\section{PENDAHULUAN}

Pendidikan merupakan salah satu hal yang tidak dapat dipisahkan dari manusia. Pendidikan mempunyai peran yang penting dalam meningkatkan kualitas suatu bangsa. Berdasarkan hal tersebut, maka disusunlah sebuah UU Nomor 20 Tahun 2003, yang menyatakan bahwa pendidikan adalah usaha sadar dan terencana untuk mewujudkan suasana belajar dan proses pembelajaran agar peserta didik secara aktif mengembangkan potensi dirinya untuk memiliki kekuatan spiritual keagamaan, pengendalian diri, kepribadian, kecerdasan, akhlak mulia, serta keterampilan yang diperlukan dirinya, masyarakat, bangsa dan negara.. Trianto [1] menyatakan bahwa "pendidikan hendaknya melihat jauh ke depan dan memikirkan apa yang akan dihadapi peserta didik 
di masa yang akan datang”. Perkembangan dunia pendidikan akan selalu mengikuti kemajuan Ilmu Pengetahuan dan Teknologi (IPTEK). Kemajuan dalam teknologi yang berkembang pesat harus diimbangi dengan sumber daya manusia yang berkualitas agar nantinya dapat bersaing di era globalisasi.

Pendidikan IPA merupakan salah satu program pembelajaran yang diharapkan dapat menjadi wahana bagi siswa untuk mempelajari diri sendiri dan alam sekitar, serta prospek pengembangan lebih lanjut dalam penerapannya di dalam kehidupan sehari-hari. Proses pembelajarannya menekankan pada pemberian pengalaman langsung untuk mengembangkan kompetensi agar menjelajahi dan memahami alam sekitar secara ilmiah [2].

Pembelajaran IPA sebenarnya suatu hal yang menyenangkan, menggembirakan, dan mengasyikkan, tetapi hal ini ada kalanya akan terbalik menjadi sesuatu yang tidak menyenangkan dan membosankan. Guru sebagai fasilitator, motivator serta organisator harus mampu memahami cara dan gaya belajar peserta didiknya. Menurut DePorter dan Henarcki [3] gaya belajar merupakan kombinasi dari bagaimana seseorang dapat menyerap dan kemudian mengatur serta mengolah informasi.

Peserta didik di setiap kelas tentu memiliki cara dan gaya belajar yang berbeda-beda, sehingga kemampuan menganalisis dan menyerap informasi berbeda-beda pula. Ada peserta didik yang hanya paham materi pelajaran apabila guru mengadakan kegiatan diskusi dan presentasi, menampilkan gambar atau video yang berkaitan dengan meteri pelajaran serta bersentuhan langsung dengan meteri pelajaran melalui kegiatan percobaan dan jelajah alam sekitar. Oleh karena itu guru harus pandai dalam memilih model pelajaran yang tepat, namun kenyataannya selama ini, masih banyak guru yang menggunakan model pembelajaran konvensional sehingga kegiatan pembelajaran lebih pasif dan berpusat pada guru (teacher center). Kegiatan pembelajaran yang hanya berpusat pada guru akan membuat siswa cepat merasa bosan dan kurang termotivasi untuk memahami materi pelajaran. Hal tersebut terlihat dari hasil observasi yang telah dilaksanakan di SMPN 3 Gunungsari, ketika proses pembelajaran sedang berlangsung terdapat beberapa siswa yang bermain dan mengobrol dengan teman sebangkunya, menggambar di buku tulis, dan tidak memperhatikan penyampaian dari guru.

Motivasi belajar adalah suatu perubahan tenaga di dalam diri seseorang (pribadi) yang ditandai dengan timbulnya perasaan dan reaksi untuk mencapai tujuan [4]. Kurangnya motivasi belajar siswa akan berdampak pada hasil belajar yang rendah. Hasil belajar merupakan penilaian terhadap kriteria tertentu untuk mencapai tujuan yang diharapkan dimiliki siswa setelah menyelesaikan pengalaman belajarnya [5].

Syah [6] menyebutkan ada beberapa faktor yang mempengaruhi hasil belajar siswa, salah satunya adalah faktor pendekatan belajar (approach to learning) yaitu jenis upaya belajar yang meliputi strategi, model dan metode yang digunakan siswa untuk melakukan kegiatan pembelajaran pada materi-materi pelajaran. Oleh karena itu, agar peserta didik lebih termotivasi dalam belajar dan hasil belajarnya lebih optimal, maka diperlukan suatu model pembelajaran yang inovatif.

Model pembelajaran $V A K$ merupakan alternatif baru yang di modifikasi dengan modalitas yang dimiliki oleh siswa. Model pembelajaran $V A K$ adalah model pembelajaran yang mengkombinasikan ketiga gaya belajar (melihat, mendengar dan bergerak) setiap individu dengan cara memanfaatkan potensi yang telah dimiliki dengan melatih dan mengembangkannya, agar semua kebiasaan belajar siswa terpenuhi [7]. Penerapan model pembelajaran ini di kelas memiliki kelebihan yaitu dapat mengaitkan pengalaman siswa dengan bantuan modalitas yang ada pada diri siswa yaitu penglihatan (visual), pendengaran (auditory) dan gerakan tubuh (kinesthetic) dan di akhir pelajaran siswa mendapatkan sebuah penghargaan dari hasil kerjanya yang dapat memacu mental dan memotivasi siswa-siswa yang lain, sehingga pembelajaran dapat lebih bermakna [8]. Hal ini berarti bahwa menggunakan kombinasi modalitas visual, auditori dan kinestetik dalam belajar akan mempermudah siswa dalam menyerap, menyaring dan mengolah informasi yang mereka dapatkan dari proses pembelajaran yang berlangsung.

Berdasarkan latar belakang tersebut, maka tujuan dalam penelitian ini adalah untuk mengetahui pengaruh model pembelajaran Visual Auditorial Kinestetik (VAK) terhadap motivasi dan hasil belajar IPA biologi siswa kelas VIII SMPN 3 Gunungsari tahun ajaran 2015/2016.

\section{METODE PENELITIAN}

Jenis penelitian ini adalah eksperimen semu (quasi experiment). Desain penelitian yang digunakan adalah non equivalent control group design. Penelitian ini dilaksanakan pada semester ganjil dari bulan Agustus sampai September di SMPN 3 Gunungsari tahun ajaran 2015/2016. Populasi dalam penelitian ini adalah seluruh siswa kelas VIII yang terbagi dalam tiga kelas, sampel ditentukan dengan teknik simple random sampling dan diperoleh kelas VIII B sebagai kelas 
eksperimen (menggunakan model $V A K$ ) dan kelas VIII C sebagai kelas kontrol (menggunakan model ekspositori). Materi yang diajarkan dalam penelitian ini adalah sistem gerak.

Variabel bebas dalam penelitian ini adalah model pembelajaran $V A K$ dan variabel terikatnya adalah motivasi dan hasil belajar siswa. Instrumen yang digunakan dalam penelitian ini berupa lembar angket motivai belajar dengan empat alternatif jawaban (sangat setuju, setuju, tidak setuju, sangat tidak setuju) dan lembar tes hasil belajar berupa soal-soal dalam bentuk pilihan ganda dengan 4 pilihan jawaban yaitu A, B, C, D. Uji validitas dalam penelitian ini menggunakan teknik korelasi product moment dengan bantuan SPSS 17 for windows, sedangkan uji reliabilitas menggunakan rumus Alpha Cronbach untuk angket motivasi belajar dan rumus Spearman Brown untuk tes hasil belajar dengan bantuan SPSS 16 for windows. Untuk uji hipotesis menggunakan uji-t jenis independent sample t-test.

\section{HASIL DAN PEMBAHASAN}

Hasil angket motivasi belajar siswa pada kelas VIII B yang diberi perlakuan dengan menggunakan model pembelajaran $V A K$ memperoleh skor rata-rata sebesar 83,33, sedangkan kelas VIII C yang diberi perlakuan dengan menggunakan model ekspositori memperoleh skor rata-rata sebesar 77,64. Hasil belajar pretest siswa pada kelas VIII B memperoleh nilai rata-rata sebesar 36,83 dan posttest sebesar 81,83 , sedangkan hasil belajar pretest siswa pada kelas VIII C memperoleh nilai rata-rata sebesar 33,45 dan posttest sebesar 69,27.

Uji normalitas yang digunakan dalam penelitian ini menggunakan metode kolmogrovsmirnov dengan bantuan SPSS 17 for windows. Kriteria yang berlaku pada pedoman SPSS Indonesia [9] adalah sebagai berikut:

a. Jika signifikansi yang diperoleh $>\alpha$, maka sampel data berasal dari populasi yang berdistribusi normal.

b. Jika signifikansi yang diperoleh $<\alpha$, maka sampel data bukan berasal dari populasi yang berdistribusi normal.

Berdasarkan hasil uji normalitas menggunakan SPSS 17 for Windows pada kolom Kolmogrov-Smirnov diketahui bahwa data motivasi dan hasil belajar siswa baik pada kelas eksperimen maupun kelas kontrol semuanya terdistribusi normal, dimana nilai signifikansinya lebih besar dari 0,05 .

Uji homogenitas bertujuan untuk mengetahui apakah varians data bersifat homogen atau heterogen. Uji homogenitas dianalisis menggunakan Levene's test dengan bantuan SPSS 16 for Windows. Kriteria yang berlaku pada pedoman SPSS Indonesia [9] adalah sebagai berikut :

a. Jika signifikansi yang diperoleh $>\alpha$, maka variansi setiap sampel sama (homogen).

b. Jika signifikansi yang diperoleh $<\alpha$, maka variansi setiap sampel tidak sama (heterogen).

Berdasarkan hasil uji homogenitas menggunakan SPSS 17 for Windows, diperoleh tingkat signifikansi data motivasi belajar sebesar 0,999 dan tingkat signifikansi data hasil belajar sebesar 0,450 , hal ini berarti tingkat signifikansi kedua data lebih besar dari 0,05, sehingga data motivasi dan hasil belajar memiliki varians yang homogen.

Uji hipotesis dianalisis dengan menggunakan uji statistik parametrik yaitu uji-t jenis independent sample t-test dengan bantuan SPSS 16 for Windows dengan ketentuan data terdistribusi normal. Uji ini terdiri dari dua macam yaitu uji-t pooled varians digunakan jika diasumsikan kedua varians data homogen (equal variance assumed) dan uji-t separated varians digunakan jika diasumsikan kedua varians data heterogen (equal variance not assumed). Ketentuan uji hipotesis adalah sebagai berikut:

a. Jika $t_{\text {hitung }}>t_{\text {tabel}}$, maka (Ho) ditolak dan (Ha) diterima, yang berarti bahwa terdapat pengaruh model pembelajaran visual auditorial kinestetik (VAK) terhadap motivasi belajar IPA Biologi siswa. Jika $t_{\text {hitung }}<t_{\text {tabel, }}$ maka (Ho) diterima dan (Ha) ditolak, yang berarti bahwa tidak terdapat pengaruh model pembelajaran visual auditorial kinestetik $(V A K)$ terhadap motivasi belajar IPA Biologi siswa.

b. Jika thitung $>t_{\text {tabel}}$, maka (Ho) ditolak dan (Ha) diterima, yang berarti bahwa terdapat pengaruh model pembelajaran visual auditorial kinestetik (VAK) terhadap hasil belajar IPA Biologi siswa. Jika $t_{\text {hitung }}<t_{\text {tabel, }}$ maka (Ho) diterima dan (Ha) ditolak, yang berarti bahwa tidak terdapat pengaruh model pembelajaran visual auditorial kinestetik (VAK) terhadap hasil belajar IPA Biologi siswa.

Berdasarkan hasil perhitungan uji hipotesis data motivasi belajar pada taraf signifikan $5 \%$ atau $\alpha=0,05$ dengan derajad kebebasan $n_{1}+n_{2}$ $2=24+22-2=44$, diperoleh nilai $t_{\text {hitung }}$ sebesar 3,411 lebih besar dari nilai $t_{\text {tabel }}$ sebesar 1,680 $(3,411>1,680)$. 
Tabel 1. Hasil Uji Normalitas Data Motivasi dan Hasil Belajar

\begin{tabular}{|c|c|c|c|c|}
\hline \multicolumn{4}{|c|}{ Test of Normality } & \multirow[t]{3}{*}{ Keteragan } \\
\hline & \multirow[t]{2}{*}{ Kelas } & \multicolumn{2}{|c|}{ Kolmogorov - smirnov } & \\
\hline & & Statistic & Sig. & \\
\hline \multirow[t]{2}{*}{ Motiasi Belajar } & Eksperimen & 0.160 & 0.113 & Normal \\
\hline & Control & 0.180 & 0.062 & Normal \\
\hline \multirow{2}{*}{ Hasil Belajar } & Eksperimen & 0.122 & 0.200 & Normal \\
\hline & Kontrol & 0.173 & 0.087 & Normal \\
\hline
\end{tabular}

Tabel 2. Hasil Uji Homogenitas Data Motivasi dan Hasil Belajar

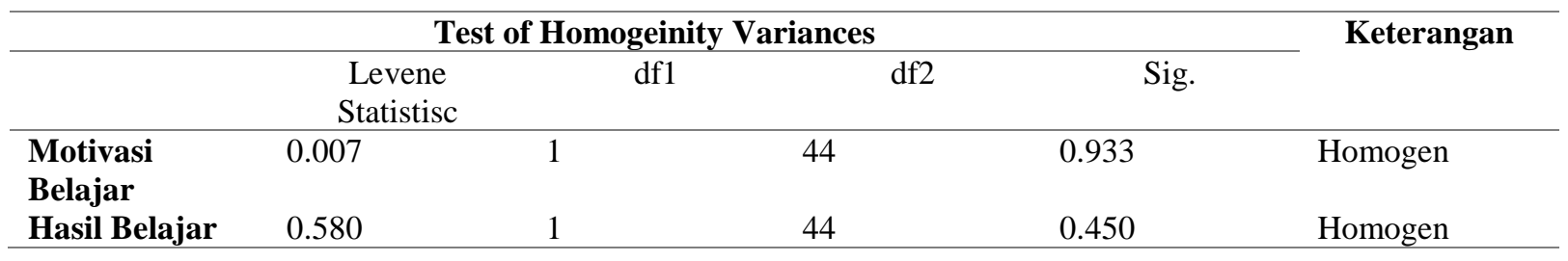

Tabel 3. Hasil Uji Hipotesi Motivasi Belajar

\begin{tabular}{|c|c|c|c|c|c|c|c|c|}
\hline \multicolumn{9}{|c|}{ Independent Samples Test } \\
\hline & & \multicolumn{7}{|c|}{ t-test for Equality Means } \\
\hline & & \multirow[t]{2}{*}{$\mathrm{t}$} & \multirow[t]{2}{*}{ df } & \multirow[t]{2}{*}{$\begin{array}{l}\text { Sig. }(2 \\
\text { tailed) }\end{array}$} & \multirow[t]{2}{*}{$\begin{array}{c}\text { Mean } \\
\text { Deference }\end{array}$} & \multirow[t]{2}{*}{$\begin{array}{l}\text { Std. Error } \\
\text { Diference }\end{array}$} & \multicolumn{2}{|c|}{$\begin{array}{l}95 \% \text { Confidence } \\
\text { Interval of the }\end{array}$} \\
\hline & & & & & & & Lower & Upper \\
\hline \multirow[t]{6}{*}{ Motivvasi } & Equal & 3.411 & 44 & 0.001 & 5.697 & 1.670 & 2.331 & 9.063 \\
\hline & Variance & & & & & & & \\
\hline & Asummed & & & & & & & \\
\hline & Equal & 3.404 & 43.173 & 0.001 & 5.697 & 1.674 & 2.322 & 9.072 \\
\hline & Variance not & & & & & & & \\
\hline & Asummed & & & & & & & \\
\hline
\end{tabular}

Tabel 4. Hasil Uji Hipotesi Hasil Belajar Siswa

\begin{tabular}{|c|c|c|c|c|c|c|c|c|}
\hline \multicolumn{9}{|c|}{ Independent Samples Test } \\
\hline & & \multicolumn{7}{|c|}{ t-test for Equality Means } \\
\hline & & \multirow[t]{2}{*}{$\mathrm{t}$} & \multirow[t]{2}{*}{ df } & \multirow[t]{2}{*}{$\begin{array}{l}\text { Sig. (2 } \\
\text { tailed) }\end{array}$} & \multirow[t]{2}{*}{$\begin{array}{c}\text { Mean } \\
\text { Deference }\end{array}$} & \multirow[t]{2}{*}{$\begin{array}{l}\text { Std. Error } \\
\text { Diference }\end{array}$} & \multicolumn{2}{|c|}{$\begin{array}{l}95 \% \text { Confidence } \\
\text { Interval of the }\end{array}$} \\
\hline & & & & & & & Lower & Upper \\
\hline \multirow{5}{*}{$\begin{array}{l}\text { Hasil } \\
\text { Belajar } \\
\text { (gain) }\end{array}$} & Equal & 3.285 & 44 & 0.002 & 8.652 & 2.633 & 3.344 & 13.959 \\
\hline & Variance & & & & & & & \\
\hline & Asummed & 3314 & 43461 & 0002 & 8652 & 2610 & 3380 & 13014 \\
\hline & Variance not & 5.014 & 45.401 & & 0.052 & 2.010 & 5.589 & 15.914 \\
\hline & Asummed & & & & & & & \\
\hline
\end{tabular}

Dengan demikian dapat dinyatakan bahwa $\mathrm{H}_{0}$ ditolak dan $\mathrm{H}_{\mathrm{a}}$ diterima, yang berarti terdapat pengaruh model pembelajaran Visual Auditorial Kinestetik (VAK) terhadap motivasi belajar IPA Biologi siswa. Hal ini sejalan dengan penelitian Sugiarti [10] menyatakan bahwa penerapan model pembelajaran $V A K$ dapat meningkatkan motivasi belajar siswa sehingga berdampak pada meningkatnya prestasi belajar siswa. Penelitian lain yang sejalan dengan penelitian ini adalah penelitian yang dilakukan oleh Akbar [11] menunjukkan bahwa model quantum teaching (tipe VAK) sangat berpengaruh terhadap motivasi belajar siswa, jika motivasi siswa tinggi maka proses belajar mengajar akan terasa lebih menyenangkan dan aktivitas belajar siswa meningkat. Tingginya motivasi belajar siswa pada penggunaan model pembelajaran $V A K$ juga didukung oleh penelitian 
Kristina \& Purba [12] yang menyatakan bahwa gaya belajar $V A K$ berpengaruh positif terhadap motivasi belajar siswa. Dalam proses belajar mengajar, motivasi merupakan salah satu faktor yang diduga besar pengaruhnya terhadap hasil belajar. Siswa yang memiliki motivasi yang tinggi diduga akan memperoleh hasil belajar yang baik. Pentingnya motivasi belajar siswa terbentuk antara lain agar terjadi perubahan belajar ke arah yang lebih positif. Pandangan ini sesuai dengan pendapat Prayitno [13] yang menyatakan bahwa siswa yang termotivasi dengan baik dalam belajar melakukan kegiatan lebih banyak dan lebih cepat, dibandingkan dengan siswa yang kurang termotivasi dalam belajar.

Berdasarkan hasil perhitungan uji hipotesis data hasil belajar pada taraf signifikan $5 \%$ atau $\alpha=0,05$ dengan derajad kebebasan $n_{1}+n_{2}-2=$ $24+22-2=44$ diperoleh nilai $t_{\text {hitung }}$ sebesar 3,285 lebih besar dari nilai $t_{\text {tabel }}$ sebesar 1,680 (3,285 $>1,680)$.

Dengan demikian $\mathrm{H}_{\mathrm{o}}$ ditolak dan $\mathrm{H}_{\mathrm{a}}$ diterima, yang berarti bahwa terdapat pengaruh model pembelajaran Visual Auditorial Kinestetik (VAK) terhadap hasil belajar IPA Biologi siswa. Hal ini sejalan dengan penelitian yang dilakukan oleh Yugiana [14] menyatakan bahwa model pembelajaran visual auditori kinestetik (VAK) berbasis Open-Ended berpengaruh terhadap hasil belajar siswa. Faktor yang mempengaruhi hal tersebut diantaranya adalah karakteristik dari model pembelajaran tersebut yang menekankan pada modalitas (gaya belajar) yang dimiliki oleh siswa, sehingga siswa lebih mudah dalam memahami dan menyerap materi pelajaran yang disampaikan.

DePorter dan Henarcki [15] melakukan penelitian untuk menyelidiki pengaruh pembelajaran yang memperhatikan modalitas $V A K$ siswa dalam meningkatkan hasil belajar siswa. Dalam penelitian ini diperoleh bahwa model pembelajaran guru yang memperhatikan keanekaragaman modalitas $V A K$ yang dimiliki siswa memberikan hasil yang lebih baik. Hasil ini sejalan dengan penelitian yang dilakukan oleh Ramlah dkk [16] menyatakan bahwa terdapat pengaruh yang signifikan antara modalitas belajar terhadap prestasi belajar. Rose \& Nicholl [17] mengungkapkan bahwa siswa dapat mengoptimalkan hasil belajar mereka, apabila siswa tersebut dapat belajar sesuai dengan modalitas belajarnya. Guru sebagai fasilitator dan mediator memegang peranan penting dalam mengelola pembelajaran, agar dapat memfasilitasi keanekaragaman gaya belajar yang dimiliki oleh siswa. Menurut Putranti [18], modalitas belajar yang meliputi visual, auditory, dan kinesthetic dapat menentukan hasil belajar seorang pebelajar. Apabila seorang pebelajar diberikan strategi belajar mengajar yang sesuai dengan modalitas belajarnya maka pebelajar dapat berkembang dengan lebih baik. Pemrosesan informasi dan komunikasi dari pengajar ke pebelajar akan berjalan dengan baik sehingga pebelajar dapat memahami pelajaran dengan baik.

Proses pembelajaran dengan model pembelajaran $V A K$ membantu siswa untuk lebih aktif selama pembelajaran berlangsung sehingga guru lebih berfungsi sebagai fasilltator pembelajaran dan motivator bagi siswa dalam mengembangkan pengetahuan, keterampilan, dan sikap-sikap. Lestari dkk [19] menyatakan bahwa aktivitas belajar siswa selama diterapkannya strategi pembelajaran berbasis $V A K$ cenderung meningkat.

\section{PENUTUP}

\section{Kesimpulan:}

Penerapan model pembelajaran Visual Auditorial Kinestetik (VAK) berpengaruh secara signifikan terhadap motivasi dan hasil belajar IPA biologi siswa pada kelas VIII di SMP Negeri 3 Gunungsari tahun ajaran 2015/2016.

\section{Saran:}

Berdasarkan hasil penelitian yang telah dilakukan, disarankan sebagai berikut:

1. Model pembelajaran Visual Auditorial Kinestetik (VAK) dapat dijadikan sebagai salah satu alternatif dalam meningkatkan motivasi dan hasil belajar siswa dalam proses pembelajaran.

2. Bagi peneliti selanjutnya, model pembelajaran Visual Auditorial Kinestetik (VAK) dapat dicoba untuk diterapkan pada materi dan mata pelajaran serta pada jenjang pendidikan yang lain sesuai dengan kurikulum yang berlaku.

\section{DAFTAR PUSTAKA}

[1] Trianto. 2007. Model-Model PembelajaranInovatif Berorientasi Konstruktivistik. Jakarta. Prestasi Pustaka Publisher.

[2] Depdiknas. 2006. Kurikulum 2006 Kurikulum Tingkat Satuan Pendidikan (KTSP). Jakarta. Depdiknas.

[3] DePorter, B \& Hernacki, M. 1999. Quantum Learning: Membiasakan Belajar Nyaman dan Menyenangkan. Terjemahan: Alwiyah Abdurrahman. Bandung. Kaifa. 
[4] Nashar, H. 2004. Peranan Motivasi dan Kemampuan Awal dalam Pembelajaran. Jakarta. Delia Press.

[5] Sudjana, N. 2002. Dasar-Dasar Proses Belajar Mengajar. Bandung. Sinar Baru Algensindo.

[6] Syah, M. 2003. Psikologi Belajar. Jakarta. Grafindo Persada.

[7] Sugiyanto. 2008. Model-model pembelajaran Inovatif. Surakarta. Panitia.

[8] DePorter, B., Reardon, M \& Nourie. 2010. Quantum Teaching: Mempraktikkan Quantum Learning Di Ruang-Ruang Kelas. Terjemahan: Ari Nilandri. Bandung. Kaifa.

[9] Spssindonesia. Analisis Data Dengan SPSS. (online): http://www.spssindonesia.com/2014/02/do wnload-ebook-spss-gratis.html. Diakses pada tanggal 15 Agustus 2015.

[10] Sugiarti, A. 2010. Penerapan Model Pembelajaran VAK (Visual Auditory Kinestetik) dalam Pembelajaran Matematika untuk Meningkatkan Motivasi Belajar Siswa (PTK Kelas VIII SMP Muhammadiyah 2 Surakarta Tahun Ajaran 2009/2010). (Skripsi). Universitas Muhammadiyah Surakarta. (online): http://etd.eprints.ums.ac.id/7261/. Diakses pada tanggal 29 September 2015.

[11]Akbar, S. M. 2013. Pengaruh Model Quantum Teaching (Tipe VAK) terhadap Motivasi Siswa pada Standar Kompetensi Dasar-Dasar Elektronika di SMK NU Sunan Drajat Paciran Lamongan. Jurnal Pendidikan Teknik Elektro Universitas Negeri Surabaya. (online): http://ejournal.unesa.ac.id/article/9051/44/ article.pdf. Diakses pada Tanggal 20 Okrober 2015.

[12] Kristina, F \& Purba. 2012. Pengaruh Penggunaan Gaya Belajar Visual Auditorial Kinestetik (VAK) dalam Meningkatkan Motivasi dan Hasil Belajar
Siswa SMA pada Pokok Bahasan Larutan Elektrolit dan Non Elektrolit. Jurnal Pendidikan Kimia UNIMED. (online): http://digilib.unimed.ac.id/. Diakses pada Tanggal 20 Oktober 2015.

[13] Prayitno, E. 1989. Motivasi dalam Belajar dan Berprestasi. Jakarta. PPPLPTK.

[14] Yugiana, M. I., Wiarta, W. I \& Suniasih, W.N. 2013. Model Pembelajaran VAK Berbasis Open-Ended Berpengaruh terhadap Hasil Belajar Matematika Siswa Kelas V SD Gugus Srikandi Denpasar Timur. Jurnal PGSD UNDIKSHA.(online):http://ejournal.undik sha.ac.id/index.php/JJPGSD/article/view/1 860. Diakses pada Tanggal 20 Oktober 2015.

[15]DePorter, B \& Hernacki, M. 2005. Quantum Learning: Membiasakan Belajar Nyaman dan Menyenangkan. Bandung. Kaifa.

[16] Ramlah., Firmansyah, D \& Zubair, H. 2014. Pengaruh Gaya Belajar dan Keaktifan Siswa terhadap Prestasi Belajar Matematika (Survei pada SMP Negeri di Kecamatan Klari Kabupaten Karawang). Jurnal Ilmiah Solusi Vol. 1 No. 3. (online): http://digilib.unsika.ac.id/sites/default/files . Diakses pada Tanggal 29 September 2015.

[17] Rose, C \& Nicholl, J. 2002. Accelerated Learning. Bandung. Nuansa.

[18] Putranti, N. Gaya Belajar Visual Auditori Kinestetik.(online): http://nuritaputrianti.wordpress.com. Diakses pada tanggal 29 September 2015.

[19]Lestari, A., Yarman \& Syfriandi. 2012. Penerapan Strategi Pembelajaran Matematika Berbasis Gaya Belajar Vak (Visual Auditorial Kinestetik). Jurnal Pendidikan FMIPA UNP Vol 1 No. 1 Tahun 2012. (online): http://ejournal.unp.ac.id/students/index.ph p/pmat/article/download/1195/887. Diakses pada Tanggal 20 April 2015 